\section{For she's a jolly good fellow: Happy Birthday, PAGES!}

Hubertus Fischer' ${ }^{1}$ S. Fritz ${ }^{2}$ and M.N. Evans ${ }^{3}$

In a human life, reaching 30 years is usually a notable milestone. The teething troubles are long behind us, the endless school days are over, perhaps a university degree is in our pocket, there are no parents to tell us what to do and what not to do, and, if we're lucky, we have a stable income and a career underway. It is the time where we feel that we have achieved something important and that our actions have an impact.

As with all analogs, this one has its limits, but having edited this special 30-year anniversary issue of the Past Global Changes Magazine (which contains articles that look at the past, present, and future of PAGES from various perspectives), we feel that 30 years is not such a bad age for PAGES either. Born as an idea of a few visionary and influential climate scientists 30 years ago (see: overbearing parents above), PAGES has overcome obstacles and growing pains, developing from a small structure into a vibrant interdisciplinary body, and has certainly left its mark on the climate research landscape.

Of course, some boundary conditions have always governed what the PAGES objectives were, but within this framework PAGES has been a leader in filling a void in climate and sustainability research. PAGES members have synthesized observations and reconstructions from paleoclimatic archives, in conjunction with models, to identify processes and changes in the Earth system and use them to put the present and future climate into context.
Thirty years may also be the age where we realized that growth may not just be in the vertical direction but may also proceed sideways, and that we have to exercise more and make a greater effort to stay fit than we did in previous years. Certainly, the sphere of scientific questions and the composition of the community of PAGES has grown oblate over the years. PAGES is now a community of almost 5500 subscribers, 15 working groups, and more than 500 active working group members. The last PAGES Open Science Meeting in Zaragoza, Spain, drew a crowd of nearly 900 ! So yes, PAGES has grown both in length and girth, but its vast science output shows that it has never been fitter. The articles in this issue, a sample of working groups combined with a series of articles by the PAGES Early-Career Network, attest not only to the excellent output and the imprint left by PAGES on Earth Sciences, but also to the promise of more from the next generation of PAGES leaders.

Success does not necessarily always follow growth and experience, but we are optimistically looking into the future. With a stable financial background secured for the coming decade, it is essentially up to the PAGES members to fill its science plan with new, innovative ideas, science questions and paleoscience perspectives, and insights relevant for the challenges that lie ahead for mankind in terms of climate change, biodiversity loss, and a sustainable use of natural resources. Looking at the many earlycareer researchers who are carrying PAGES

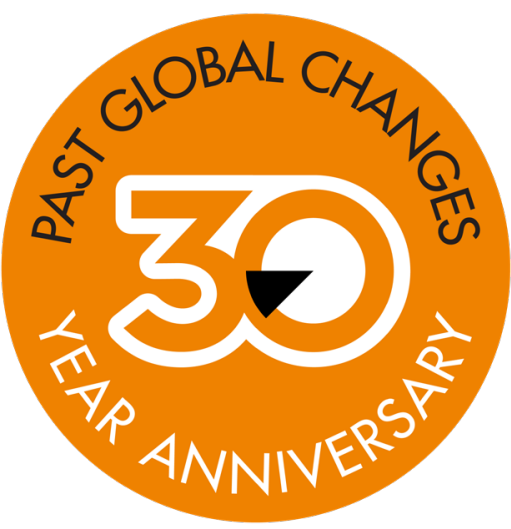

forward and infusing PAGES with new ideas (as shown in the series of articles in the section "Highlighting the future of past global change research" in this magazine), there is little to worry about.

As is common when celebrating such a round anniversary, there is always someone standing up to give a sometimes mildly funny and often too-long speech on behalf of the person celebrating the jubilee. We don't want to be that someone, so we had better stop here. But as is also customary in these cases, we cannot resist toasting PAGES:

\section{"To the next 30 !"}

And why not?!

\section{AFFILIATIONS}

'Climate and Environmental Physics, Physics Institute and Oeschger Centre for Climate Change Research University of Bern, Switzerland

'Department of Earth and Atmospheric Sciences,

School of Biological Sciences, University of Nebraska, Lincoln, USA

${ }^{3}$ Department of Geology and ESSIC, University of Maryland, College Park, USA

\section{CONTACT}

Hubertus Fischer: hubertus.fischer@climate.unibe.ch

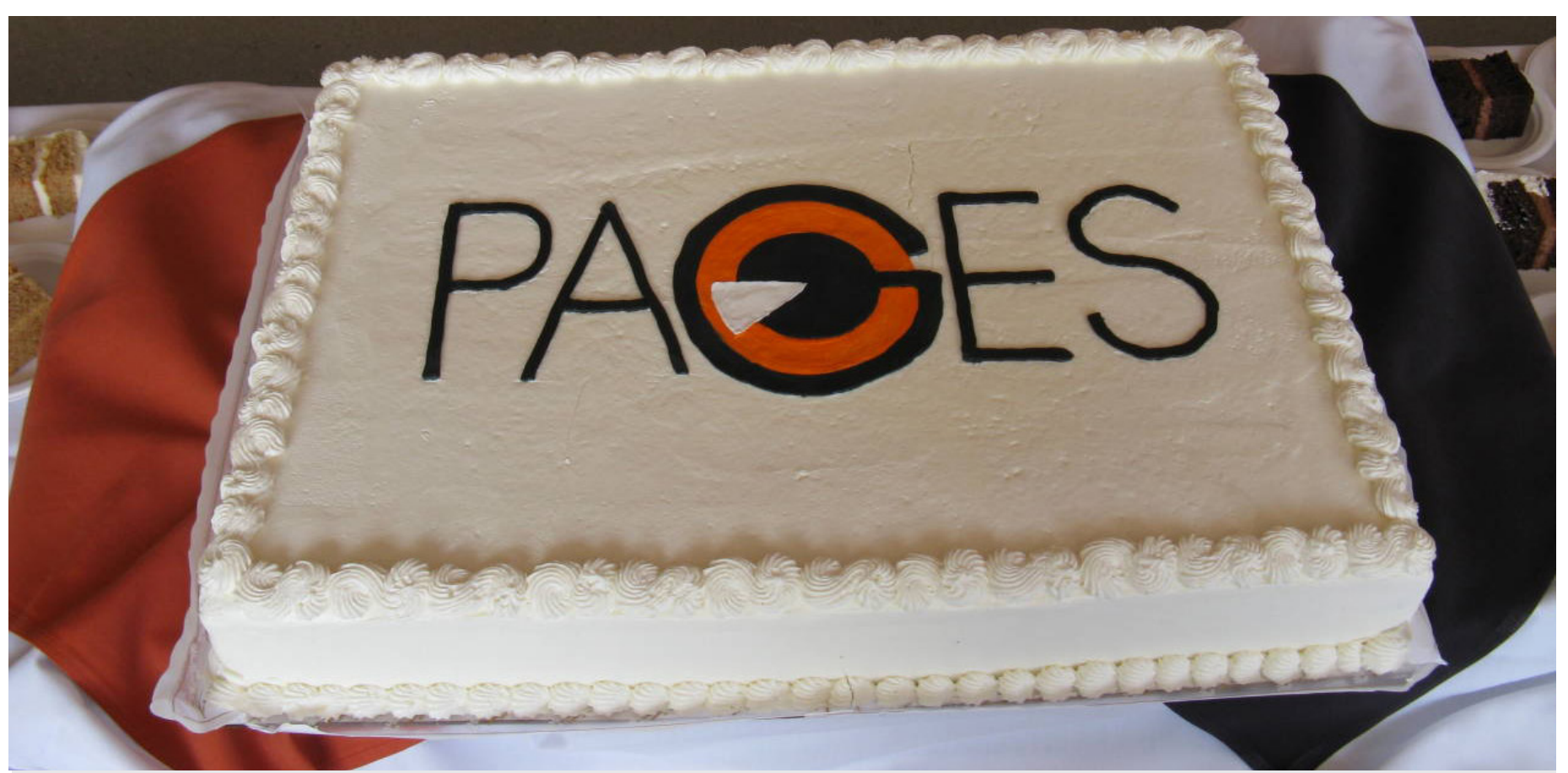

Figure 1: PAGES also celebrated reaching adulthood th the PAGES 3rd Open Science Meeting in Corvallis, OR, USA, in 2009 (Image credit: Nick Rackebrandt). 